\title{
The traffic mode choice model based on fuzzy order theory
}

\author{
Lin Zhang, Nana Lv, Ke Wu \\ College of Mathematics and Information Science, Nan Chang Hang Kong University, 330063, Nan \\ Chang, Jiangxi, China
}

zhjiaoxue@163.com, 286634603@qq.com, wwkkdl@163.com

\begin{abstract}
Keywords: attention point; travel attribute; fuzzy weight; traffic mode choice; fuzzy order method Abstract: In order to investigate the effect of traffic mode choice for travel attributes from travel attention point, the multi-objective fuzzy order model was established for different travelers by fuzzy methods. Considering the travelers' ages, careers, and other factors, all kinds of travelers' travel attention point weights and close degrees were obtained by using triangular fuzzy numbers. The traffic order values were obtained and travelers got the preferred traffic mode by constructing the fuzzy order choice mode. The example indicates that below 35 years old and over 60 travelers, bus or subway was the first choice, 36 to 59 years old travelers preferred transportation was private cars. The decision process of the choice of traffic mode was simulated by the fuzzy method, the research of model could provide the basis for urban traffic structure optimization and transportation policy strategy.
\end{abstract}

\section{Introduction}

The travelers' traffic mode choices determine the structure of the urban traffic in a large extent. With the development of economy and urbanization, residents can choose diverse traffic modes. According to the travel attributes, a reasonable choice of traffic mode is a necessary way to ease urban traffic congestion problems.

Many research about the traffic mode choice were developed, many different models and algorithms were gave out, and gave out different models and algorithms[1,2]. Ben et al analyzed the traffic mode choice by using discrete form, and established the traffic demand model[3]. According to different influence on travel factors to traffic mode choices, Wallace et al constructed a negative two regression model[4]. The relevant policies of Traffic Demand Management (TDM) were made by the relative effects of the travel attributes to travel behavior. These models described the factors influencing the traffic mode choice by the precise number, but many factors were involved and difficult to quantified. So there are some limitations.

Fuzzy mathematics[5] enable the study of the mathematics communication between mathematical certainty objects and mathematical uncertainty by certain fuzzy objects with the fuzzy set theory. Therefore, the fuzzy multi-objective attribute model for different types of travelers is established by combining the uncertain factors of affecting traffic choice and the deterministic data based on the fuzzy mathematics, and the fuzzy multi-objective model is solved by using the fuzzy order method. It explains behavior details of travelers choose traffic modes.

\section{The attention point}

In a city let $N=\{1,2, \cdots, n\}$ be a set of all travelers, where the total number of travelers is $n$. Before the trip, travelers have fast, province, convenient, comfortable, safety attention points. Assume that the traveler has $z$ attention points, and make $h_{i}^{k}$ the first attention point of $i$ for the traveler $k$, where $0<i \leq z$ and $i$ is an integer. Let $M=\{1,2, \cdots, m\}$ represents a set that the travelers' choice of traffic mode consisting of, which $m$ is the sum number of traffic modes. 
For any traffic mode $j \in M$, the traveler $k \in N$ chooses the traffic mode $j$ to satisfy the degree of $h_{i}^{k}$ for the attention point $h_{i}^{k}$, it is a fuzzy quantity, and noted the fuzzy number, ${ }^{\tilde{h}_{i j}^{k},} \tilde{h}_{i j}^{k}$ represents a close degree that the traffic mode $j$ achieve $k$ 's attention point $h_{i}^{k}$.

\section{The travel attribute and fuzzy weight}

Since different travelers for the same attention point of the importance of evaluation is different, so according to the importance of travelers' own individual attention points, travelers give different attention points corresponding weights. Let the fuzzy weight vector of the traveler $k$ to all attention points is:

$$
\tilde{\lambda}^{k}=\left(\tilde{\lambda}_{1}^{k}, \tilde{\lambda}_{2}^{k}, \cdots, \tilde{\lambda}_{z}^{k}\right)^{\mathrm{T}}
$$

where $^{t} \tilde{\lambda}_{i}^{k}(i=1,2, \cdots, z)$ is the weight that the traveler $k$ to the attention point $h_{i}^{k}$, and ${ }^{\tilde{\lambda}_{i}^{k}}$ is the fuzzy number.

Travelers' ages and careers are different, the fuzzy weights are often different.

The influence of ages on attention points: the different ages of the travelers, the attention degree to the attention point is different. So according to travelers' ages, the corresponding weight evaluations to the attention points are given. Suppose that set $S=\{1,2, \cdots, s\}$ represents age groups of all travelers, for any age group $q \in S$, the attention degree of the travelers belonging to the $q$ age group to the attention point $i$ is a fuzzy quantity, and marked $\tilde{\sim}^{\tilde{q}}$.

The influence of careers on attention points: the different careers of the travelers, the preference degree to the attention point is different. The careers can be divided into students, civil servants, managers, ordinary workers, unemployed retirees and so on. Let $G=\{1,2, \cdots, g\}$ be a set that occupation classifications of all travelers, For any occupation classification $t \in G$, the preference degree to the attention point $i$ is a fuzzy quantity, and denoted as $\tilde{l}_{i}^{t}$.

For any traveler $k \in N$, the comprehensive index to the weight of the attention point $h_{i}^{k}$ can be marked by multiplying the attention degree $\tilde{w}_{i}^{q}$ and the preference degree $\tilde{l}_{i}^{t}$. Namely,

$$
\tilde{\lambda}_{i}^{k}=\tilde{w}_{i}^{q} \times \tilde{l}_{i}^{t}
$$

Here, ${ }^{\tilde{\lambda}_{i}^{k}}$ represents the comprehensive evaluation index of the traveler $k$ that $q$ group of ages and $t$ kind of careers to the attention point $h_{i}^{k}$.

\section{The fuzzy multi-objective order method}

The process of travelers choose traffic modes naturally is a multi-objective decision problem. In order to judge the merits of each traffic mode to an attention point, the following the merits of $M$ traffic modes are confirmed by using the fuzzy optimization method.

There are a number of attention points when travelers choose traffic modes, and these attention points are corresponding to the expectation values. The evaluation of the traveler $k$ to the close degree $\tilde{h}_{i j}^{k}$ more approaches the expectation value, then the fuzzy membership degree more 
approaches one, so the fuzzy membership degree of the close degree $\tilde{h}_{i j}^{k}$ to the attention point $h_{i}^{k}$ by the triangle fuzzy number is expressed as:

$$
u_{h_{i j}^{k}}(x)=\left\{\begin{array}{cl}
\frac{x-a_{i j}^{k}}{b_{i j}^{k}-a_{i j}^{k}} & x \in\left[a_{i j}^{k}, b_{i j}^{k}\right] \\
\frac{c_{i j}^{k}-x}{c_{i j}^{k}-b_{i j}^{k}} & x \in\left(b_{i j}^{k}, c_{i j}^{k}\right] \\
0 & \text { others }
\end{array}\right.
$$

It's noted $\tilde{h}_{\ddot{b}}^{k}=\left(a_{i j}^{k}, b_{i j}^{k}, c_{i j}^{k}\right)$, which $a_{i j}^{k}$ is the lower bound value of the traveler $k$ the close degree $\tilde{h}_{i j}^{k}$; $b_{i j}^{k}$ and $c_{i j}^{k}$ respectively is the expectation and upper bound value.

The attention degree $\tilde{w}^{\tilde{q}}$ and the preference degree ${ }^{\tilde{l}_{i}^{t}}$ are the fuzzy numbers, and their triangular fuzzy numbers respectively are $\tilde{w}_{i}^{q}=\left(\eta_{i}^{q}, \delta_{i}^{q}, \theta_{i}^{q}\right)$ and $\tilde{l}_{i}^{t}=\left(\varphi_{i}^{t}, \phi_{i}^{t}, \psi_{i}^{t}\right)$. So the fuzzy membership degree of the standardized fuzzy weight $\tilde{\lambda}_{i}^{k}$ is expressed as:

$$
\tilde{\lambda}_{i}^{k}=\left(\eta_{i}^{q} \varphi_{i}^{t}, \delta_{i}^{q} \phi_{i}^{t}, \theta_{i}^{q} \psi_{i}^{t}\right)
$$

where $\eta_{i}^{q} \varphi_{i}^{t}, \delta_{i}^{q} \phi_{i}^{t}$ and $\theta_{i}^{q} \psi_{i}^{t}$ respectively represents the lower bound, expectation upper bound value of the evaluation to the weight $\tilde{\lambda}_{i}^{k}$.

The fuzzy multi-objective decision mainly solves the comprehensive evaluation to the choice of the traffic mode, the purpose is to make the overall evaluation of the traveler $k$ choices the traffic mode $j$, which form a new comprehensive index by being combined with the corresponding close degree $^{\tilde{h}_{i j}^{k}}$ and the weight $\tilde{\lambda}_{i}^{k}$. The close degree $\tilde{h}_{i j}^{k}$ and the weight ${ }^{\tilde{\lambda}_{i}^{k}}$ is weighted aggregated. Namely,

$$
\tilde{r}_{j}^{k}=\tilde{\lambda}_{i}^{k} \times \tilde{h}_{i j}^{k}
$$

Among that , $\tilde{r}_{\ddot{j}}^{k}=\left(\eta_{i}^{q} \varphi_{i}^{t} a_{i j}^{k}, \delta_{i}^{q} \phi_{i}^{t} b_{i j}^{k}, \theta_{i}^{q} \psi_{i}^{t} c_{i j}^{k}\right)$.

According to the weighted aggregation ${ }^{r_{i j}^{k}}$, the comprehensive evaluation value of the traffic mode $j$ is obtained by summing all the attention points of ${ }^{\tilde{r}^{k}}{ }^{k}$.

$$
\tilde{Y}_{j}^{k}=\sum_{i=1}^{z} r_{i j}^{k} \quad j=1,2, \ldots, m ; k=1,2, \cdots, n
$$

Thus, the fuzzy membership degree about the comprehensive evaluation value $\widetilde{Y}_{j}^{k}$ is:

$$
\tilde{Y}_{j}^{k}=\left(y_{j 1}^{k}, y_{j 2}^{k}, y_{j 3}^{k}\right)
$$


Here, $y_{j 1}^{k}=\sum_{i=1}^{z} \eta_{i}^{q} \varphi_{i}^{t} a_{i j}^{k}, y_{j 2}^{k}=\sum_{i=1}^{z} \delta_{i}^{q} \phi_{i}^{t} b_{i j}^{k}, y_{j 3}^{k}=\sum_{i=1}^{z} \theta_{i}^{q} \psi_{i}^{t} c_{i j}^{k} ; y_{j 1}^{k}, y_{j 2}^{k}$ and $y_{j 3}^{k} \quad$ respectively is the lower bound, expectation and the upper bound value.

Next, the comprehensive evaluation values are ordered. The expectation value more can reflect the comprehensive evaluation, so the traffic order values are obtained by using the average area. There is a sort $P^{k}$ of all traffic modes. Namely,

$$
P^{k}\left(\widetilde{Y}_{j}^{k}\right)=\frac{y_{j 1}^{k}+y_{j 2}^{k}+y_{j 3}^{k}}{3}
$$

The merit order of the traffic modes is obtained by the above analysis calculation, the traveler $k$ thereby chooses the best traffic mode.

\section{Example}

For example, the ages, occupations and trip purposes of travelers in a city are divided into four segments, five categories and four categories respectively. Travelers' attention points are divided into five categories: economy, accessibility, convenience, comfort and security. The corresponding evaluations of different attribute travels to the attention points are obtained by telephone interviews and other methods. As shown in Table 1.

Table1 Semantic Items of Travel Attention Points Evaluation for travelers with different attributes

\begin{tabular}{|c|c|c|c|c|c|c|}
\hline & & Economy & Accessibility & Convenience & Comfort & Safety \\
\hline \multirow{4}{*}{ Age groups } & $1: 10 \sim 18$ ages & $\begin{array}{c}\text { Less } \\
\text { important }\end{array}$ & Important & Important & $\begin{array}{c}\text { Less } \\
\text { important }\end{array}$ & $\begin{array}{c}\text { Very } \\
\text { important }\end{array}$ \\
\hline & $2: 19 \sim 35$ ages & $\begin{array}{c}\text { Very } \\
\text { important }\end{array}$ & $\begin{array}{c}\text { Very } \\
\text { important }\end{array}$ & Not important & $\begin{array}{c}\text { Not } \\
\text { important }\end{array}$ & Medium \\
\hline & $3: 36 \sim 60$ ages & $\begin{array}{c}\text { Not } \\
\text { important }\end{array}$ & Important & Not important & Important & Important \\
\hline & $4:$ over 60 ages & $\begin{array}{c}\text { Less } \\
\text { important }\end{array}$ & Not important & $\begin{array}{c}\text { Very } \\
\text { important }\end{array}$ & Important & $\begin{array}{c}\text { Very } \\
\text { important }\end{array}$ \\
\hline \multirow{5}{*}{$\begin{array}{l}\text { Occupational } \\
\text { groups }\end{array}$} & 1 : Civil servant & Medium & Important & Important & $\begin{array}{c}\text { Less } \\
\text { important }\end{array}$ & Medium \\
\hline & $\begin{array}{c}2: \text { Enterprises } \\
\text { personnel }\end{array}$ & Important & $\begin{array}{c}\text { Very } \\
\text { important }\end{array}$ & Medium & $\begin{array}{c}\text { Not } \\
\text { important }\end{array}$ & $\begin{array}{c}\text { Less } \\
\text { important }\end{array}$ \\
\hline & $\begin{array}{c}3: \text { Individual } \\
\text { owners }\end{array}$ & Important & Medium & Important & $\begin{array}{c}\text { Less } \\
\text { important }\end{array}$ & $\begin{array}{c}\text { Not } \\
\text { important }\end{array}$ \\
\hline & $4:$ Students & $\begin{array}{c}\text { Not } \\
\text { important }\end{array}$ & $\begin{array}{c}\text { Very } \\
\text { important }\end{array}$ & Medium & $\begin{array}{c}\text { Not } \\
\text { important }\end{array}$ & $\begin{array}{c}\text { Very } \\
\text { important }\end{array}$ \\
\hline & $\begin{array}{l}5: \text { Unemployed } \\
\text { retirees }\end{array}$ & $\begin{array}{c}\text { Very } \\
\text { important }\end{array}$ & Not important & Medium & $\begin{array}{c}\text { Less } \\
\text { important }\end{array}$ & Medium \\
\hline
\end{tabular}

Let $\mathrm{K}_{\mathrm{qtd}}$ show the traveler that $\mathrm{q}(\mathrm{q}=1,2,3$ or4 $)$ age group and $\mathrm{t}(\mathrm{t}=1,2,3,4$ or5 $)$ occupational group. According to the different ages and occupations, there are 11 types of travelers $(1+5+4+1=11)$.

Travelers can choose traffic modes by bus, subway and private car. Each type of travelers to various traffic mode has a semantic evaluation. Assume that students don't have private cars, then the corresponding semantic evaluation close degree is assigned zero.

In order to quantify the above semantic evaluation, the fuzzy triangle number of the semantic items is given. 


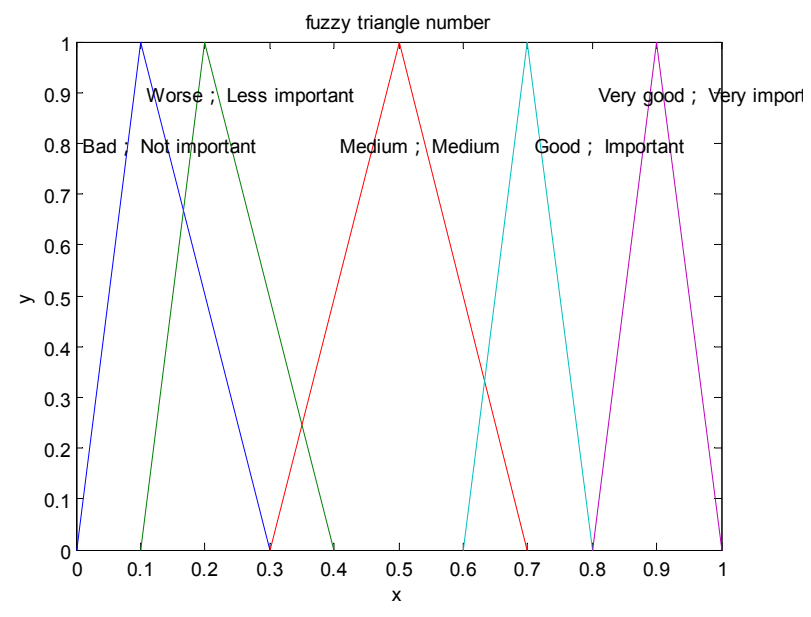

The table 1 and the figure 1 showed that the corresponding weight triangle fuzzy numbers of different attention points were obtained.

In order to convenient drawing, it's numbering types of traveler now. Table2 is the corresponding relation between serial numbers and types of travelers.

Table2 The Corresponding Relation between serial numbers and types of travelers

\begin{tabular}{|c|c|c|c|c|c|c|c|c|c|c|c|}
\hline Numbers & 1 & 2 & 3 & 4 & 5 & 6 & 7 & 8 & 9 & 10 & 11 \\
\hline Types & $\mathrm{K}_{14}$ & $\mathrm{~K}_{21}$ & $\mathrm{~K}_{22}$ & $\mathrm{~K}_{23}$ & $\mathrm{~K}_{24}$ & $\mathrm{~K}_{25}$ & $\mathrm{~K}_{31}$ & $\mathrm{~K}_{32}$ & $\mathrm{~K}_{33}$ & $\mathrm{~K}_{35}$ & $\mathrm{~K}_{45}$ \\
\hline
\end{tabular}

The traveler will be more inclined to choose this traffic mode of the higher order value. The order values of all 11 types of travelers to traffic modes are obtained by the number in Table 2 as the horizontal ordinate, marked the types of travelers, the order values as longitudinal coordinate.

Fig.2 Order Values of All Transportation Modes for travelers

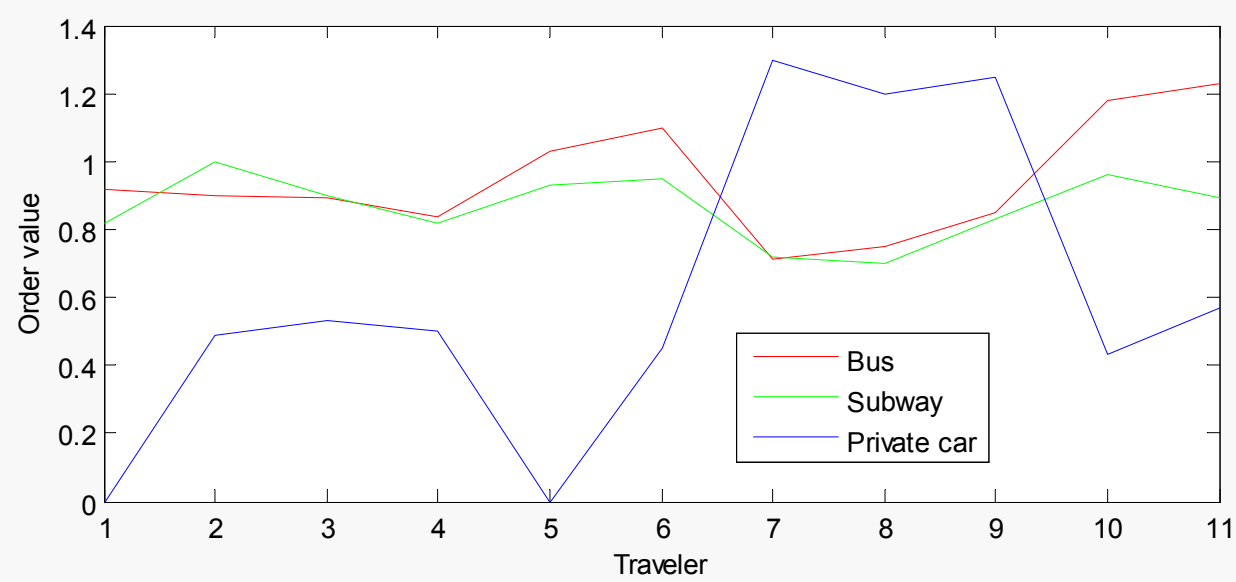

From the figure 2, the bus and subway of travelers below 35 years old order values were higher, distributing between 0.8 to 1.2 ; the private car of travelers 36 to 59 years old order (in addition to leaving staffs)value was higher, distributing between 1 to 1.3 ; the bus and subway of travelers over 60 order values were higher, distributing between 1.2 to 1.3. Bus was the students and retirees preferred traffic mode. The order values were above 0.9 .

\section{Conclusion}

In this paper, the multi-objective fuzzy attribute model were established by obtaining the fuzzy numbers of travel attributes and attention points. According to quantifying different traffic modes, the order to traffic modes was obtained. Based on the above analysis, the decision-making process of the choice of traffic mode was simulated by the fuzzy method, and reflecting the process of thinking, the research of model could provide the basis for urban traffic structure optimization and 
transportation policy strategy. The next step is to analyze the influence of the choice of traffic modes from the point of view of travel time, income level and the changes of urban traffic policy.

\section{Acknowledgements}

This research is supported by National Natural Science Foundation of China under Grant No. 51368046 and Natural Science Foundation of Jiangxi Province of China under Grant No. $20151 \mathrm{BAB} 201028$.

\section{Reference}

[1] Garling Tommy, Kwan M P, Golledge R G. Computational-process modeling of household activity scheduling [J]. Transportation Research B,1994,28(5):355-364

[2] Jou Rongchang, Chen Chih-Cheng, Chen, Yung-Lin. The effects of travel satisfaction of unimplemented transportation demand management strategies on travel behavior [J]. Transportmetrica, 2011, 7(7):201-228.

[3] M.E., Ben-Akiva, S.R., Leman. Discrete choice analysis: theory and application to travel demand [J]. Operational Research Society,1987,38(4):370-371.

[4] Wallace B., Barnes J., Rutherford G.S.. Evaluating the effects of traveler and trip characteristics on trip chaining, with implications for transportation demand management strategies [J]. Transportation Research Record Journal of the Transportation Research Board, 2000,1718(1):97-106.

[5] Li Deng-feng. Fuzzy Multi-objective Many-Person Decision Makings and Games[M]. Beijing: National defence industry Press,2002. 